\title{
Update and critical appraisal of combined timolol and carbonic anhydrase inhibitors and the effect on ocular blood flow in glaucoma patients
}

This article was published in the following Dove Press journal:

Clinical Ophthalmology

27 March 2010

Number of times this article has been viewed

\section{Adam M Moss \\ Alon Harris \\ Brent Siesky \\ Deepam Rusia \\ Kathleen MWilliamson \\ Yochai Shoshani \\ Department of Ophthalmology, Indiana University School of Medicine, Indianapolis, Indiana, USA}

Correspondence: Alon Harris Lois Letzter Professor of Ophthalmology, Professor of Cellular and Integrative Physiology, Indiana University School of Medicine, 702 Rotary Circle, Room I37, Indianapolis, IN 46202, USA $\mathrm{Tel}+\mathrm{I}$ (3I7) 278-0I77

Fax +I (317) 278-1007

Email alharris@indiana.edu
Abstract: Topical hypotensive therapy with both timolol and carbonic anhydrase inhibitors has been shown to be efficacious at reducing intraocular pressure. Many prospective studies have also suggested that carbonic anhydrase inhibitors augment ocular blood flow and vascular regulation independent of their hypotensive effects. Although consistent in their findings, these studies must be cautiously interpreted due to the limitations of study design and specific blood flow imaging modalities. The purpose of this review is to appraise and critically evaluate the current body of literature investigating the effects of combined treatment with topical carbonic anhydrase inhibitors and timolol in patients with glaucoma with respect to ocular blood flow, visual function, and optic nerve head structure.

Keywords: ocular blood flow, carbonic anhydrase inhibitor, timolol, glaucoma, visual function, optic nerve head

\section{Introduction}

\section{Open angle glaucoma and vascular risk factors}

Glaucoma is a chronic progressive optic neuropathy resulting in optic nerve damage and irreversible loss of visual function for which elevated intraocular pressure (IOP) is currently the only modifiable risk factor. ${ }^{1}$ Several large studies including the Ocular Hypertension Study, ${ }^{2}$ the Early Manifest Glaucoma Trial,,${ }^{3,4}$ the Collaborative Normal Tension Glaucoma Study, ${ }^{5}$ the Advanced Glaucoma Intervention Study, ${ }^{6,7}$ and the Collaborative Initial Glaucoma Treatment Study ${ }^{8}$ have emphasized that despite the benefits of IOP reduction, many patients with open angle glaucoma (OAG) will continue to experience disease progression. The existence of normal tension glaucoma (NTG) further suggests that other risk factors may play an important role in the disease process. Other important risk factors have been recently established, and there is increasing evidence that ocular blood flow changes and other vascular risk factors play a large role in the development and progression of glaucoma.

Vascular abnormalities have long been suggested as a possible contributing factor to the pathophysiology of OAG. Several prospective clinical trials have revealed blood flow alterations in various tissue beds of the eye in glaucoma patients. Chung et al found that NTG is characterized by a substantial decrease in capillary perfusion of the peripapillary retina. ${ }^{9}$ Yin et al demonstrated significantly delayed choroidal filling time in primary OAG patients. ${ }^{10}$ Similarly, several studies have revealed blood flow alterations in the retrobulbar circulations of glaucoma patients. ${ }^{11-14}$

One of the most recognized vascular risk factors in glaucoma is ocular perfusion pressure (OPP). OPP is calculated as the difference between two-thirds of the mean 
arterial blood pressure (BP) and IOP and is the driving force of ocular blood flow. OPP is often subdivided into systolic perfusion pressure (SPP) and diastolic perfusion pressure (DPP). Lower OPP has recently been determined to be an independent risk factor for $\mathrm{OAG}$, a consensus point reached by the 2009 World Glaucoma Association. ${ }^{15}$ This was due, in part to significant findings from large studies such as the Baltimore Eye Survey, where subjects with DPP less than $30 \mathrm{mmHg}$ were 6 times more likely to develop primary OAG than subjects with a DPP of greater than $50 \mathrm{mmHg} .{ }^{16}$ This finding is consistent with the Barbados Eye Study ${ }^{17}$ and the Egna-Neumarkt Study. ${ }^{18}$ Additionally, evidence suggests that subjects with glaucoma fail to adapt to changes in either IOP or BP that cause fluctuations in OPP, ultimately resulting in unstable blood flow to the retina and optic nerve head. ${ }^{19}$

\section{Topical OAG therapies}

\section{$\beta$-Blockers}

Topical OAG therapies have long been utilized with a primary goal of lowering IOP. In order to be efficacious, such therapies must penetrate the anterior surface of the eye, reach critical concentrations in the tissue of interest, and exert the desired physiologic effect. Topical medications may also be absorbed systemically leading to additional desired or adverse effects on ocular tissue and vasculature.

One of the most commonly prescribed topical OAG therapies is timolol maleate, a non-selective $\beta$-adrenergic receptor blocking agent. Timolol works to reduce IOP by blocking $\beta$-adrenergic receptors on the ciliary epithelium thereby reducing aqueous humor production. In addition to production of aqueous humor, $\beta$-adrenergic receptors are involved in the mediation of vascular smooth muscle relaxation. ${ }^{20}$ Blockade of $\beta$-adrenergic receptors have been previously shown to induce vasoconstriction in various tissues. ${ }^{20-22}$ Within the eye, $\beta$-adrenergic receptors have been identified in the retina and optic nerve head tissues. ${ }^{23,24}$ This has led to a concern that $\beta$-adrenergic receptor blocking agents may cause local vasoconstriction in addition to IOP reduction. ${ }^{24}$ The effect of timolol on ocular blood flow in glaucoma patients however has been controversial. Several studies utilizing diverse measurement techniques have found varying results, ranging from significantly decreased to significantly increased effects on ocular blood flow, with many showing no significant change. ${ }^{25-34}$ There has not been a consistent effect of timolol in altering ocular blood flow, therefore timolol is often considered limited in terms of its affects on the ocular vasculature. Further detailed information on beta blockers and ocular hemodynamics are thoroughly discussed in several previously published articles. ${ }^{25-27}$

\section{Carbonic anhydrase inhibitors}

Carbonic anhydrase inhibitors (CAI) are another class of topical medications commonly prescribed for the treatment of OAG. Carbonic anhydrase, an enzyme integral to fluid balance in the human body, catalyzes the reversible reaction of carbon dioxide $\left(\mathrm{CO}_{2}\right)$ and water $\left(\mathrm{H}_{2} \mathrm{O}\right)$ into carbonic acid. Carbonic acid then further dissociates into protons and bicarbonate. In the ciliary body of the eye, bicarbonate ions formed during this reaction are actively transported across the ciliary epithelial membrane, drawing water into the posterior chamber via osmosis, forming aqueous humor. CAI bind to the active site of the enzyme and prevent catalytic conversion of $\mathrm{CO}_{2}$ and $\mathrm{H}_{2} \mathrm{O}$ into bicarbonate and a proton, and vice versa. This process disrupts normal physiologic mechanisms and leads to different effects in different tissues. In the eye, CAI specifically inhibit the CA-II isoform, which is concentrated in the ciliary body. Inhibition of this enzyme has been shown to decrease IOP by decreasing aqueous humor production.

The effects of CAI on vascular tissue are also of great interest. Originally, systemic CAI were utilized for the treatment of patients with OAG. Early research on one such systemic CAI, acetazolamide (AZA), documented its vasodilatory effects on the cerebrovascular circulation. Laux et al demonstrated that intravenous administration of AZA significantly increases cerebral blood flow (CBF) through increasing $\mathrm{PaCO}_{2}$ and decreasing cerebral oxygen consumption by restricting the Bohr Effect in capillaries of the brain. Well established in the literature, seven independent studies have reported a significant increase in $\mathrm{CBF}$ after intravenous administration of AZA. ${ }^{35}$ These data led others to propose that a similar mechanism might be present in the retinal circulation as the two vascular tissue beds share many similarities. Stanescu et al demonstrated that b-wave amplitude, a measure of bipolar cell function in the retina, as measured by electroretinogram significantly increased following intravenous administration of AZA. ${ }^{36}$ The known vasoactive properties of CAI have inspired extensive study of the effects of topical CAI on ocular blood flow, with dorzolamide and brinzolamide being the most prescribed and researched. ${ }^{37}$

\section{Combined treatments}

The Ocular Hypertensive Treatment Study ${ }^{2}$ and the Collaborative Initial Glaucoma Treatment Study ${ }^{38}$ showed that $40 \%$ and $75 \%$ of patients, respectively, required two or 
more medications to adequately control their IOP. This illustrates that although $\beta$-blocker therapy is frequently used as an initial therapy, it may be inadequate to achieve optimal IOP reduction. Several large studies have shown that a combined treatment with dorzolamide and timolol reduces aqueous production and IOP to a greater degree than is achieved by either agent alone. ${ }^{39,40}$ Similarly, in a large randomized controlled trial including 523 subjects, a fixed combination of brinzolamide and timolol was shown to be superior to either drug used alone with regards to its IOP-lowering efficacy. ${ }^{41}$

It is important to acknowledge that there are many classes of ocular hypotensive agents used for the management of OAG. Many drugs increase perfusion pressure by reducing IOP. However among the various hypotensive drug classes, CAI have demonstrated a consistent effect on ocular blood flow that is independent of IOP. ${ }^{37}$ Some data support the ability of CAI to enhance ocular blood flow regulation and suggest that the increase in blood flow exceeds that which is expected from their ocular hypotensive effect alone ${ }^{42}$ The observed increase in ocular blood flow is likely caused by vasodilation of local ocular vessels, which has previously been reported to result from CAI-induced metabolic acidosis and subsequent elevation of carbon dioxide levels. ${ }^{43}$ This article will review CAI and their combined use with timolol in terms of their effects on the ocular circulation.

\section{Carbonic anhydrase inhibitors and ocular blood flow}

A variety of imaging technologies have been used to examine the effects of topical CAI on ocular blood flow. Each imaging technology has specific sites of measurement and inherent shortcomings. Therefore it is important to consider the limitations of each imaging technology alongside the documented effects of CAI and their potential implications.

\section{Pulsatile ocular blood flow}

Several studies have documented increased pulsatile ocular blood flow (POBF) in subjects with OAG receiving a combination of dorzolamide and timolol. It is important to note that POBF and ocular pulse amplitude (OPA) measurements are not methodologies which directly measure any aspect of ocular blood flow. They instead measure the fluctuation in IOP which may represent some aspect of total orbital pulse and perfusion, but this has not been established. Januleviciene et al compared the effects of dorzolamide/timolol fixed combination (DTFC) to those of latanoprost with respect to IOP and POBF in a randomized, open-label, cross-over study of 30 subjects with $\mathrm{OAG} .{ }^{44}$ In this investigation there were no differences between the two study arms with respect to baseline IOP and POBF, and both treatments were found to similarly reduce IOP. However, DTFC increased pulse volume by 0.767 microliters $(P=0.0087)$ while latanoprost was not found to have a significant effect $(P=0.2407)$. These findings supported those from an earlier study by Manni et al in which the substitution of DTFC in place of timolol was found to similarly enhance POBF. ${ }^{45}$ The pulsatile component of ocular blood flow is believed to be measured by the ocular pulse amplitude (OPA) during POBF measurement. Schmidt et al investigated the effects of DTFC compared to that of timolol alone and found that DTFC significantly increased OPA while timolol alone had no effect. ${ }^{46}$ In patients with glaucoma, higher OPA has been shown to correlate with less severe glaucoma ${ }^{47}$ Since POBF and OPA are based upon IOP measurements, it is unclear how POBF and OPA would differ significantly if measurements were done at different time points in a 24-hour day, especially in patients who exhibit night time/early morning dipping of systemic blood pressure or diurnal changes in IOP. Assessing diurnal fluctuations in IOP, blood pressure, and ocular blood flow are an area of needed research in glaucomatous patients.

These data suggest that augmentation of ocular blood flow may occur during of treatment with CAI. However, it should be noted that POBF and OPA are not direct measures of ocular blood flow, so study results should be interpreted with caution. Further, inter-individual variations have been shown to limit POBF analysis, although a coefficient of reliability of 0.92 has been documented.$^{48}$ Also, the relatively small sample sizes and use of single imaging technologies limits interpretation on the comprehensive impact of DTFC on ocular blood flow.

\section{Color Doppler imaging}

The most widely utilized imaging technology for investigating ocular blood flow in humans is color Doppler imaging (CDI) ${ }^{49} \mathrm{CDI}$ has been utilized in dozens of studies which have investigated the effects of CAI on the retrobulbar circulation. Siesky et al compared the effects of DTFC and latanoprost plus timolol in a randomized, double-blind, cross-over study involving 16 patients. ${ }^{50}$ Both therapies produced statistically similar reductions of IOP $(12.2 \%$ and $13.9 \%$, respectively; $P=0.5533$ ) with similar heart rate and BP between treatments, suggesting minimal systemic vascular alterations with topical use. In this study, only DTFC was associated with an increase in retrobulbar blood flow velocities as measured by CDI. DTFC significantly increased end diastolic velocity (EDV) $(P=0.0168)$ and decreased the 
resistance to flow $(P=0.0279)$ in the central retinal artery (CRA). Peak systolic velocity (PSV) and EDV of the temporal posterior ciliary artery (PCA) were both increased by DTFC $(P=0.0125$ and 0.0238 , respectively). In vivo and in vitro studies have illustrated that parallel increases in PSV and EDV may be interpreted as an increase in volumetric blood flow. ${ }^{51,52}$ Of note, there were no significant differences in retinal hemodynamics as measured by Heidelberg retinal flowmetery (HRF), and there were no changes in visual function measured by visual acuity and contrast sensitivity.

Another study of the retrobulbar blood vessels by Uva et al compared DTFC to combined treatment with pilocarpine and timolol in 16 patients with OAG. ${ }^{53}$ The authors reported that although the latter treatment resulted in a greater decrease in IOP, only treatment with DTFC was associated with increased EDV and lower resistive index (RI) in the CRA $(P<0.01)$. In another prospective, randomized, cross-over study involving 22 subjects newly diagnosed with OAG, Martinez et al assessed the effects of DTFC and latanoprost on retrobulbar hemodynamics and IOP. ${ }^{54}$ IOP and CDI measurements, including PSV, EDV, and RI in the ophthalmic artery (OA) and short PCA, were similar at baseline. Both therapies were found to be equally efficacious at reducing IOP, however, only treatment with DTFC significantly increased the EDV and decreased the RI in the OA and short PCA. A similar 32-subject, prospective, cross-over study comparing DTFC and a fixed combination of latanoprost and timolol (LTFC) found that while both treatments significantly lowered IOP only DTFC had beneficial vascular effects on retrobulbar vessels in patients with newly diagnosed OAG ${ }^{55}$ In this study DTFC decreased the RI in the OA and short PCA while LTFC was found to increase RI in both vessels. A statistically significant increase in EDV in the OA and PCA was found with DTFC.

Other CAI, such as brinzolamide, have also been studied in combination with timolol for the treatment of primary OAG. In a 5-year prospective study, 146 participants were randomized to either dorzolamide $2 \%$ or brinzolamide $1 \%$, each added to timolol $0.5 \% .{ }^{56}$ The investigators found that dorzolamide, but not brinzolamide, augmented blood flow when added to timolol. Though both treatment arms similarly decreased IOP, only the combination of dorzolamide and timolol was associated with an increased EDV and decreased $\mathrm{RI}$ in the OA, short PCA, and CRA. A transient increase in retrobulbar flow was seen in the subjects receiving brinzolamide, which lasted for 6 months in the CRA and 12 months in the short PCA. These findings are in direct contrast to the many studies which suggest brinzolamide has similar blood flow influences to dorzolamide. ${ }^{37}$ The authors suggest that the differing vasoactive effects of brinzolamide and dorzolamide may be explained by differing levels of inhibition of the carbonic anhydrase isoenzyme IV located in the endothelial cells of the choriocapillaris, as dorzolamide has 6.5 times the inhibitory activity of brinzolamide. ${ }^{43,57}$ It is more likely, however, that specific study limitations resulted in the differences including inclusion of patients with elevated blood pressure and cardiovascular disease, insufficient study power to detect changes in the brinzolamide group $(\mathrm{n}=35)$, and grouping of the short posterior ciliary arteries into a single parameter. More research is required to know for certain if differences exist between topical CAI treatments.

Though well-validated, CDI is not without limitations, the most significant being the inability to measure vessel diameter. Although CDI is very useful for measuring blood flow velocity and vascular resistance, this limitation prevents the measurement of volumetric blood flow and requires that assumptions be made when interpreting hemodynamic parameters. A significant degree of operator dependence is inherent to CDI, and due to study design, several of the previously mentioned studies did not document an index of reproducibility. As with POBF, many of the studies utilize only CDI limiting interpretation on the comprehensive impact of DTFC on ocular blood flow. For detailed analysis of CDI reproducibility see articles by Harris et al. ${ }^{58-60}$

\section{Scanning laser ophthalmoscopy}

Scanning laser ophthalmoscopy is one of the only imaging technologies that provides direct visualization of the retinal microcirculation and has shown CAI-induced increases in retinal and choroidal circulations. Specifically, dorzolamide has been shown to accelerate retinal dye transit as measured by scanning laser ophthalmoscopy. ${ }^{61}$ In a 9-subject, openlabel, cross-over study, Harris et al compared dorzolamide to betaxolol with respect to IOP reduction, arteriovenous passage time (AVP), and blood flow velocity in the retrobulbar vessels. Both medications were found to have similar hypotensive actions. Neither drug was found to alter the retrobulbar hemodynamics as measured by CDI. Dorzolamide, but not betaxolol, was found to accelerate inferotemporal arteriovenous passage of fluorescein dye. This acceleration of dye transit could be due to direct attenuation of vascular resistance or to venodilation. The authors speculate that regional variations in retinal responsiveness may explain why the increase was limited to the inferotemporal retina as regionally differing levels of responsiveness to vasodilator and vasoconstrictor stimuli have been documented. ${ }^{62}$ 
In another study, Harris et al found that when compared with timolol, DTFC results in a greater decrease in AVP time (2.13 to 1.76 seconds, $P=0.01)$ in the superior retinal vasculature. ${ }^{63}$ Combined treatment also resulted in a greater IOP reduction (14.7 to $13.4 \mathrm{mmHg}, P<0.05$ ), making it difficult to determine if the reported hemodynamic changes are IOP-independent.

These findings must be carefully interpreted as shortened transit time is not a direct index of retinal blood flow. ${ }^{64}$ Nonetheless, acceleration of AVP has been shown to be consistent with increased blood flow suggesting CAI increases retinal blood flow. ${ }^{65}$ As with other investigations using different devices, relatively small sample sizes also limit interpretation. Further, the relatively invasive nature of scanning laser ophthalmoscopy and subsequent dye injections has limited its continued use in blood flow research in recent years.

\section{Summary}

Many imaging modalities are used to measure different hemodynamic parameters, each with its own advantages and limitations. Certain assumptions must be made with each technology, and therefore the interpretation of individual hemodynamic parameters must be assessed with caution. Relatively small sample sizes and many investigations utilizing only a single blood flow methodology further inhibit definitive analysis. Nevertheless, there is a growing body of evidence demonstrating that CAI possess the ability to augment ocular blood flow. The most comprehensive analysis on the subject, a recent meta-analysis of 13 studies conducted between 1966 and 2006 , revealed that treatment with topical CAI was associated with increased ocular blood flow velocities in the CRA, primary retinal artery branches, and short PCA. ${ }^{37}$

The mechanism by which CAI may elevate retinal, chorodial, and retrobulbar blood flow remains unclear. Increased ocular perfusion pressure via IOP reduction is one likely mechanism. However, in several studies, CAI have been found to increase ocular blood flow compared to other treatments with similar IOP reduction. Therefore, an IOP-independent mechanism of increasing ocular circulation during CAI may be present. It is plausible that carbonic anhydrase inhibition may directly relax local resistance in vessels as systemic CAI have been known to increase both cerebral ${ }^{66}$ and retinal ${ }^{67}$ blood flow by pressure independent mechanisms. Blockade of carbonic anhydrase in local tissues may therefore increase tissue $\mathrm{CO}_{2}$ concentrations and/or lower tissue $\mathrm{pH}$ resulting in vascular dilation and increased blood flow. ${ }^{67-70}$ With the limitations of current technology and the limited body of work that exists, current theories of the direct effects of CAI on ocular blood flow require further study.

While both dorzolamide and brinzolamide CAI have been available for some time, the fixed combination brinzolamide $1 \%$ and timolol $0.5 \%\left(\right.$ Azarga $\left.^{\circledR}\right)$ has recently been introduced for treatment of OAG. Azarga has been shown in a randomized controlled trial of 523 patients to significantly lower IOP more than either monotherapy. ${ }^{71}$ The effects of Azarga on ocular blood flow and ocular perfusion pressure are currently unknown.

\section{Implications of CAI treatment on long term visual function and structure}

In recent decades, many studies have revealed associations between compromised ocular blood flow, vascular dysregulation, and glaucoma. However, currently there is insufficient evidence linking the reductions in ocular blood flow to the onset or progression of glaucoma. ${ }^{72}$ Pilot research describing the relationships between OAG and decreased ocular blood flow have formed a basis for establishing the role of vascular dysregulation in the pathogenesis of glaucoma. However, only multi-center, long-term prospective investigations combining visual field (VF) and optic nerve head (ONH) structure are capable of elucidating the role of ocular blood flow as a definite risk factor for the incidence and progression of glaucomatous optic neuropathy.

\section{The relationship between ocular blood flow and visual function Ocular blood flow and visual function}

Several studies have addressed the relationship between ocular blood flow and visual function. Plange et al found that asymmetry in the visual field (VF) corresponds to asymmetrical retrobulbar blood flow velocity of glaucoma patients measured by $\mathrm{CDI} .{ }^{73}$ Zeitz et al also reported a correlation between VF progression and blood flow velocity in the short PCA which nourish the ONH. ${ }^{74}$ Galassi et al reported that patients with stable VF had higher EDV and lower vascular resistance in the OA. ${ }^{75}$ Patients with a vascular resistance greater than 0.78 in the OA had 6-times the risk of VF deterioration. Martinez et al supported this finding, suggesting a correlation between RI greater than 0.72 in the OA and increased VF progression over a period of 3 years. ${ }^{76}$ Satilmis et al also reported that lower baseline flow velocities and higher vascular resistance in the CRA were measured in patients with faster VF progression, unrelated to the extent of existing damage. ${ }^{77}$ 
Examining the retinal microcirculation, Lam et al evaluated asymmetric VF damage and retinal capillary blood flow using HRF and reported a significant decrease in blood flow in eyes with worse VF damage as compared to the fellow eye. ${ }^{78}$ Sato et al also reported that a reduction in capillary blood flow at the neuroretinal rim in normal tension glaucoma patients was associated with corresponding deterioration in $\mathrm{VF}^{79}$

Local and systemic factors other than glaucoma have also shown to affect ocular blood flow and VF outcomes. Sato et al showed that a reduction in neuroretinal rim blood flow due to scleral buckle surgery caused a progressive VF defect which stabilized after the buckle was removed. ${ }^{80}$ Improvements in ocular blood flow and mean deviation of the VF have also been observed after carotid endarterectomy. ${ }^{81}$

In a similar capacity to studies involving CAI therapies, relatively small sample sizes and many investigations utilizing only a single blood flow methodology limit the conclusions from these pilot studies. Only larger, comprehensive investigations of ocular blood flow and visual function (preferably multi-center) can definitively conclude a causal relationship between reduced ocular blood flow and glaucoma progression.

\section{Ocular blood flow and visual function in relation to $\mathrm{CAl}$}

A small number of studies have addressed the relationship between CAI, ocular blood flow, and visual function. Martinez performed a 4-year prospective study evaluating the long-term effect of adding dorzolamide $2 \%$ twice daily to timolol maleate $0.5 \%$ twice daily on IOP, retrobulbar blood flow, and VF progression in a cohort of 40 patients. ${ }^{82}$ The authors concluded that the addition of dorzolamide $2 \%$ to timolol $0.5 \%$ was associated with a significant reduction in IOP, increase in retrobulbar blood flow in the OA and short PCA, and a reduction in the risk of VF progression by $58 \%$ as compared to treatment with timolol alone. However, this study has several important limitations. Most notably, the eye with the worse VF damage was treated with dorzolamide while the fellow eye with less damage served as the control. Due to regression to the mean effect, the eye with less severe disease is more likely to experience glaucoma progression than the dorzolamide treated eye. There was a $13.1 \%$ difference in mean IOP between the dorzolamide study eye and control eye which in itself can predict reduced progression regardless of a presumed additional effect on blood flow by dorzolamide. The small sample size $(n=40)$ also limits the conclusions as a whole. The results of the study also differ substantially from the results of the European Glaucoma Prevention
Study (EGPS), ${ }^{83}$ a much larger, randomized, double-blind, controlled study. In the EGPS, 1081 patients with ocular hypertension (OHT) were enrolled by 18 European centers and were randomized to treatment with dorzolamide $2 \%$ or placebo. The efficacy end points were VF or change in $\mathrm{ONH}$ structure. Although dorzolamide reduced IOP by $15 \%-22 \%$ throughout the 5 years of the study, the EGPS failed to detect a statistically significant difference between medical therapy and placebo in reducing the incidence of OAG.

Another study evaluated visual function after application of dorzolamide, timolol or latanoprost in 14 newly diagnosed OAG patients. ${ }^{84}$ Ocular hemodynamics were assessed using fluorescein angiography by means of a scanning laser ophthalmoscope. Visual function using VF evaluation was also evaluated. Treatment with dorzolamide shortened AVP. Given that prolonged AVP times have been proven to be associated with glaucoma progression, ${ }^{85}$ it was concluded by the study that dorzolamide may provide VF and optic nerve head preservation by increasing retinal blood flow to the peripapillary ocular tissue. One significant limitation of this study was a small sample size.

A recent study published by Martinez investigated the effects of treatment with either dorzolamide $2 \%$ (DT) or brinzolamide $1 \%$ (BT), each added to timolol $0.5 \%$, over a 5-year period, with respect to VF progression. ${ }^{86}$ The study showed that VF progression correlated with lower EDV in the OA and short PCA. Treatment with DT lowered the risk for progression more significantly than BT. These findings should be cautiously interpreted since both treatments are very similar. In addition to possibly being statistically underpowered ( $\mathrm{n}=35$ for BT group), uneven inclusion of bilateral glaucoma, systemic hypertension, and cardiovascular disease as well as VFs with false positives of up to $20 \%$ limit these results.

These studies support the role of increasing ocular blood flow to preserve visual function but fail to provide adequate evidence individually. However, only larger, adequately powered, multi-center trials monitoring VF and ocular blood flow outcomes associated with various glaucoma treatments are capable of providing confirmation of these studies.

\section{The relationship between ocular blood flow and structure}

Currently, there is a lack of information on CAI treatment, blood flow, and the structure of the ONH. There have been only a few studies which have investigated the relationship between ocular blood flow and ONH structure. Logan et al reported lower retinal blood flow in glaucoma patients as 
compared to controls. ${ }^{87}$ They found a significant relationship between retinal blood flow and structural damage to the $\mathrm{ONH}$. Hafez et al showed that OAG patients had significantly lower blood flow in the ONH compared to OHT patients and normal controls. ${ }^{88}$ There was an inverse correlation between the blood flow at the neuroretinal rim and the cup to disc (C/D) ratio. In a study using CDI and scanning laser polarimetry, it was reported that OAG patients had statistically significant thinning of the retinal nerve fiber layer, reduced blood flow, and increased vascular resistance to flow as compared to age-matched healthy subjects. ${ }^{89}$

In a recent publication, Januleviciene et al compared LTFC to DTFC in a prospective, randomized, double-masked study.$^{90}$ There were similar statistically significant IOP reductions in both treatment groups. There was no difference in VF progression or retinal nerve fiber layer thickness, as measured by scanning laser polarimetry, between the two groups after one year of treatment. However, there was a statistically significant decrease in the RI of the OA and short PCA in the DTFC group compared to the LTFC group. There was also a statistically significant individual change from baseline PSV and EDV of the OA and CRA in the DTFC group.

As with the pilot data from visual function investigations, these studies are limited by relatively small sample sizes and limitations of patient populations and imaging technologies. Only larger, adequately powered multi-center trials monitoring structure and ocular blood flow outcomes associated with various glaucoma treatments are capable of providing confirmation of these pilot studies.

\section{Conclusions}

Although the World Glaucoma Association Consensus recognized that CAI have been shown to improve ocular blood flow beyond their hypotensive and perfusion pressure effects, the relationship between ocular blood flow, visual function, and $\mathrm{ONH}$ structure in patients with OAG has not been definitively established. Currently, only pilot data from small studies are available on CAI, ocular blood flow, and visual function and structure. Conclusive findings from current studies investigating the relationship between ocular blood flow, VF, and optic nerve head structure are limited by their use of differing imaging techniques, small sample sizes and methodological limitations. Current data are only suggestive of a link between ocular blood flow and glaucomatous VF loss, and only large-scale, multi-center, longitudinal studies utilizing uniform measurements of blood flow, retinal, and optic nerve structure and visual function are capable of providing sufficient evidence of such a relationship.

\section{Acknowledgment}

This work was supported in part by an unrestricted research grant from Research to Prevent Blindness, New York, NY, USA.

\section{Disclosures}

Alon Harris has been a consultant for Pfizer, Merck, Allergan and Alcon and has received grant support from Pfizer, Merck and Allergan.

\section{References}

1. Coleman AL, Kodjebacheva G. Risk factors for glaucoma needing more attention. Open Ophthalmol J. 2009;17:38-42.

2. Kass MA, Heuer DK, Higginbotham EJ, et al. The Ocular Hypertension Treatment Study: A randomized trial determines that topical ocular hypotensive medication delays or prevents the onset of primary open-angle glaucoma. Arch Ophthalmol. 2002;120:701-713.

3. Leske MC, Heijl A, Hyman L, Bengtsson B. Early Manifest Glaucoma Trial: design and baseline data. Ophthalmology. 1999;106: 2144-2153.

4. Heijl A, Leske MC, Bengtsson B, et al; Early Manifest Glaucoma Trial Study Group. Reduction of intraocular pressure and glaucoma progression: results from the Early Manifest Glaucoma Trial. Arch Ophthalmol. 2002;120:1268-1279.

5. Collaborative Normal-Tension Glaucoma Study Group. The effectiveness of intraocular pressure reduction in the treatment of normal-tension glaucoma. Am J Ophthalmol. 1998;126:498-505.

6. The Advanced Glaucoma Intervention Study (AGIS): 4. Comparison of treatment outcomes within race. Seven-year results. Ophthalmology. 1998;105:1146-1164.

7. The Advanced Glaucoma Intervention Study (AGIS): 7. The relationship between control of intraocular pressure and visual field deterioration. The AGIS Investigators. Am J Ophthalmol. 2000;130:429-440.

8. Musch D, Gillespie B, Lichter P, et al. Visual field progression in the Collaborative Initial Glaucoma Treatment Study: The impact of treatment and other baseline factors. Ophthalmology. 2009;116: 200-207.

9. Chung HS, Harris A, Kagemann L, et al. Peripapillary retinal blood flow in normal tension glaucoma. Br J Ophthalmol. 1999;83:466-469.

10. Yin ZQ, Millar TJ, et al. Widespread choroidal insufficiency in primary open-angle glaucoma. J Glaucoma. 1997;6:23-32.

11. Butt Z, McKillop G, O'Brien C, et al. Measurement of ocular blood flow velocity using colour Doppler imaging in low tension glaucoma. Eye. 1995;9:29-33.

12. Galassi F, Sodi A, Ucci F, et al. Ocular hemodynamics in glaucoma associated with high myopia. Int Ophthalmol. 1998;22:299-305.

13. Harris A, Sergott RC, Spaeth GL, et al. Color Doppler analysis of ocular vessel blood velocity in normal-tension glaucoma. Am J Ophthalmol. 1994;118:642-649.

14. Rojanapongpun P, Drance SM, Morrison BJ. Ophthalmic artery flow velocity in glaucomatous and normal subjects. Br J Ophthalmol. 1993;77:25-29.

15. Weinreb RN, Harris A, editors. Ocular Blood Flow in Glaucoma: The 6th Consensus Report of the World Glaucoma Association. Section II: Clinical Measurement of Ocular Blood Flow. Kugler Publications: Amsterdam, The Netherlands; 2009:59.

16. Tielsch JM, Katz J, Sommer A, et al. Hypertension, perfusion pressure, and primary open-angle glaucoma. A population based assessment. Arch Ophthalmol. 1995;113:216-221.

17. Leske MC, Connell AM, Wu SY, et al. Risk factors for open-angle glaucoma. The Barbados Eye Study. Arch Ophthalmol. 1995;113: 918-924. 
18. Bonomi L, Marchini G, Marraffa M, et al. Vascular risk factors for primary open-angle glaucoma: the Egna-Neumarkt Study. Ophthalmology. 2000;107:1287-1293.

19. Harris A, Jonescu-Cuypers C, Martin B, et al. Simultaneous management of blood flow and IOP in glaucoma. Acta Ophthalmol Scanda. 2001;79:336-341.

20. Nies AS, Evans GH, Shand DG. Regional hemodynamic effects of beta-adrenergic blockade with propanolol in the unanesthetized primate. Am Heart J. 1973;85:97-102.

21. Cruickshank JM. The clinical importance of cardioselectivity and lipophilicity in beta blockers. Am Heart J. 1980;100:160-178.

22. McSorley PD, Warren, DJ. Effects of propranolol and metoprolol on the peripheral circulation. Br Med J. 1978;2:1598-1600.

23. Elena PP, Kosina-Boix M, Moulin G, and Lapalus P. Autoradiographic localization of beta-adrenergic receptors in rabbit eye. Invest Ophthalmol Vis Sci. 1987;28:1436-1441.

24. Dawidek GMB, Robinson MI. Betaadrenergic receptors in human anterior optic nerve: an autoradiographic study. Eye. 1993;7:122-126.

25. Harris A, Martin B. Beta-blockers and ocular blood flow: a perspective. J Glaucoma. 1997;6:143-145.

26. Arend O, Harris A, Arend S, et al. The acute effect of topical betaadrenoreceptor blocking agents on retinal and optic nerve head circulation. Acta Ophthalmol Scand. 1998;76:43-49.

27. Evans DW, Harris A, Chung HS, et al. Effects of long term hypotension therapy with nonselective beta-blockers on ocular hemodynamics in primary open-angle glaucoma. J Glaucoma. 1999;8(1):12-17.

28. Netland PA, Schwartz B, Feke GT, Takamoto T, Konno S, Goger DG. Diversity of response of optic nerve head circulation to timolol maleate in gel-forming solution. J Glaucoma. 1999;8:164-171.

29. Fuchsjager-Mayrl G, Wally B, Rainer G, Buehl W, Aggermann T, Kolodjaschna J, et al. Effect of dorzolamide and timolol on ocular blood flow in patients with primary open angle glaucoma and ocular hypertension. Br J Ophthalmol. 2005;89:1293-1297.

30. Tamaki Y, Araie M, Tomita K, Nagahara M, Tomidokoro A. Effect of topical beta-blockers on tissue blood flow in the human optic nerve head. Curr Eye Res. 1997;16:1102-1110.

31. Evans DW, Harris A, Chung HS, Cantor LB, Garzozi HJ. Effects of long-term hypotensive therapy with nonselective beta-blockers on ocular hemodynamics in primary open-angle glaucoma. J Glaucoma. 1999;8:12-17.

32. Galassi F, Sodi A, Renieri G, Ucci F, Pieri B, Harris A, et al. Effects of timolol and dorzolamide on retrobulbar hemodynamics in patients with newly diagnosed primary open-angle glaucoma. Ophthalmologica. 2002;216:123-128.

33. Harris A, Spaeth GL, Sergott RC, Katz LJ, Cantor LB, Martin BJ. Retrobulbar arterial hemodynamic effects of betaxolol and timolol in normal-tension glaucoma. Am J Ophthalmol. 1995;120:168-175.

34. Arend O, Harris A, Wolter P, Remky A. Evaluation of retinal haemodynamics and retinal function after application of dorzolamide, timolol and latanoprost in newly diagnosed open-angle glaucoma patients. Acta Ophthalmol Scand. 2003;81:474-479.

35. Laux BE, Raichle ME. The effect of acetazolamide on cerebral bloow flow and oxygen utilization in the rhesus monkey. $J$ Clin Invest. 1978;62:585-592.

36. Stanescu B, Michiels J. The effects of acetazolamide on the human electroretinogram. Invest Ophthalmol. 1975;14:935-937.

37. Siesky B, Harris A, Brizendine E, et al. Literature review and metaanalysis of topical carbonic anhydrase inhibitors and ocular blood flow. Surv Ophthalmol. 2009;54:33-46.

38. Lichter P, Musch D, Gillespie B, et al. Interim clinical outcomes in the Collaborative Initail Glaucoma Treatment Study comparing initial treatment randomized to medications or surgery. Ophthalmology. 2001;108:1943-1953.

39. Clineschmidt CM, William RD, Snyder E, et al. A randonmized trial in patients inadequately controlled with timolol alone comparing the dorzolamide-timolol combination to monotherapy with timolol or dorzolamide. Dorzolamide-Timolol Combination Study Group. Ophthalmology. 1998;105:1952-1959.
40. Hutzelmann J, Owens S, Shedden A, et al. Comparison of the safety and efficacy of the fixed combination of dorzolamide/timolol and the concomitant administration of dorzolamide and timolol: a clinical equivalence study. International Clinical Equivalence Study Group. $\mathrm{Br}$ J Ophthalmol. 1998;82:1249-1253.

41. Kaback M, Scoper S, Arzeno G, et al. Intraocular pressure-lowering efficacy of brinzolamide $1 \% /$ timolol $0.5 \%$ fixed combination compared with brinzolamide $1 \%$ and timolol $0.5 \%$. Ophthalmology. 2008;115:1728-1734.

42. Weinreb RN, Harris A, ed. Ocular Blood Flow in Glaucoma: The 6th consensus report of the World Glaucoma Association. Section III: Clinical Relevance of Ocular Blood Flow Measurements including Effects of General Medications or A Specific Glaucoma Treatment. Kugler Publications: Amsterdam, The Netherlands; 2009:60.

43. Surgue M. Pharmacological and ocular hypotensive properties of topical carbonic anhydrase inhibitors. Prog Retin Eye Res. 2000;19:87-112.

44. Januleviciene I, Harris A, Kagemann L, et al. A comparison of the effects of dorzolamide/timolol fixed combination versus latanoprost on intraocular pressure and pulsatile ocular blood flow in primary open-angle glaucoma patients. Acta Ophthalmol Scand. 2004;82:730-737.

45. Manni G, Centofanti M, Gregori D, et al. The pulsatile ocular blood flow behaviour in open angle glaucoma patients after replacing timolol therapy with timolol and dorzolamide fixed combination: preliminary study. Acta Ophthalmol Scand. 2002;236(Suppl):55-56.

46. Schmidt KG, von Ruckmann A, Becker R, et al. Ocular pulse amplitude, intraocular pressure and beta blocker/carbonic anhydrase inhibition in combined therapy of primary open-angle glaucoma. Klin Monatsbl Augenheilkd. 1999;215:361-366.

47. Weizer JS, Asrani S, Stinnett SS, et al. The clinical utility of dynamic contour tonometry and ocular pulse amplitude. J Glaucoma. 2007;16:700-703.

48. Yang Y, Hulbert M, Batterbury M, et al. Pulsatile ocular blood flow measurements in healthy eyes: reproducibility and reference values. J Glaucoma. 1997;6:175-179.

49. Weinreb RN, Harris A, editors. Ocular Blood Flow in Glaucoma: The 6th consensus report of the World Glaucoma Association. Section II: Clinical Measurement of Ocular Blood Flow. Kugler Publications: Amsterdam, The Netherlands; 2009:21-22.

50.Siesky B, Harris A, Sines D, et al. A comparative analysis of the effects of the fixed combination of timolol and dorzolamide versus latanoprost plus timolol on ocular hemodynamics and visual function in patients with primary open-angle glaucoma. J Ocul Pharmacol Ther. 2006;22:353-361.

51. Spencer JA, Giussani DA, Moore PJ, Hanson MA, et al. In vitro validation of Doppler indices using blood and water. J Ultrasound Med. 1991;10:305-308.

52. Orge F, Harris A, Kagemann L, et al. The first technique for noninvasive measurements for volumetric ophthalmic artery blood flow in humans. Br J Ophthalmol. 2002;86:1216-1219.

53. Uva MG, Longo A, Reibaldi M, et al. The effect of timololdorzolamide and timolol-pilocarpine combinations on ocular blood flow in patients with glaucoma. Am J Ophthalmol. 2006;141:1158-1160.

54. Martınez A, Sanchez M. A comparison of the effects of $0.005 \%$ latanoprost and fixed combination dorzolamide/timolol on retrobulbar haemodynamics in previously untreated glaucoma patients. Curr Med Res Opin. 2006;22:67-73.

55. Martinez A, Sanchez M. Retrobulbar haemodynamic effects of the latanoprost/timolol and the dorzolamide/timolol fixed combinations in newly diagnosed glaucoma patients. Int J Clin Pract. 2007;61: 815-825.

56. Martinez A, Sanchez-Salorio M. A comparison of the long-term effects of dorzolamide $2 \%$ and brinzolamide $1 \%$, each added to timolol $0.5 \%$, on retrobulbar hemodynamics and intraocular pressure in open-angle glaucoma patients. J Ocul Pharm. 2009;25:239-248.

57. Stams T, Chen Y, Boriack-Sjodin PA, et al. Structures of murine carbonic anhydrase IV and human carbonic anhydrase II complexed with brinzolamide: molecular basis of isoenzyme-drug discrimination. Protein Sci. 1998;7:556-563. 
58. Harris A, Williamson TH, Martin B, et al. Test/Retest reproducibility of color Doppler imaging assessment of blood flow in orbital vessels. J Glaucoma. 1995;4:281-286.

59. Stalmans I, Siesky B, Zeyen T, et al. Reproducibilty of color Doppler imaging. Graefes Arch Clin Exp Ophthalmol. 2009;247:1531-1.

60. Quaranta L, Harris A, Donato F, et al. Color Doppler imaging of ophthalmic artery blood flow velocity: a study of repeatability and agreement. Ophthalmology. 1997;104:653-658.

61. Harris A, Arend O, Chung HS, et al. A comparative study of betaxolol and dorzolamide effect on ocular circulation in normal-tension glaucoma patients. Ophthalmology. 2000;107:430-434.

62. Chung H, Harris, Halter P, et al. Regional differences in retinal vascular reactivity. Invest Ophthalmol Vis Sci. 1999;2448-2453.

63. Harris A, Jonescu-Cuypers CP, Kagemann L, et al. Effect of dorzolamide timolol combination versus timolol $0.5 \%$ on ocular bloodflow in patients with primary open-angle glaucoma. Am J Ophthalmol. 2001;132: 490-495.

64. Weinreb R, Harris A, editors. Ocular Blood Flow in Glaucoma: The 6th consensus report of the World Glaucoma Association. Section II: Clinical Measurement of Ocular Blood Flow. Kugler Publications: Amsterdam, The Netherlands; 2009:35-38.

65. Harris A, Arend O, Arend S, et al. Effects of topical dorzolamide on retinal and retrobulbar hemodynamics. Acta Ophthalmol Scand. 1996;74:569-572.

66. Ehrenreich DL, Burns RA, Alman RW, et al. Influence of acetazolamide on cerebral blood flow. Arch Neurol. 1961;5:125-130.

67. Rassam SM, Patel V, Kohner EM. The effect of acetazolamide on the retinal circulation. Eye. 1993;7:697-702.

68. Taki K, Kato H, Endo S, et al. Cascade of acetazolamide-induced vasodilatation. Res Commun Mol Pathol Pharmacol. 1999;43:386-391.

69. Stanescu B, Michiels J. The effects of acetazolamide on the human electroretinogram. Invest Ophthalmol. 1975;14:935-937.

70. Pedersen DB, Stefánsson E, Kiilgaard JF, et al. Optic nerve $\mathrm{pH}$ and PO2: the effects of carbonic anhydrase inhibition, and metabolic and respiratory acidosis. Acta Ophthalmol Scand.

71. Kaback M, Scoper SV, Arzeno G, et al. Intraocular pressure-lowering efficacy of brinzolamide $1 \% /$ timolol $0.5 \%$ fixed combination compared with brinzolamide $1 \%$ and timolol $0.5 \%$. Ophthalmol. 2008;115: 1728-1734.

72. Weinreb R, Harris A, editors. Ocular Blood Flow in Glaucoma: The 6th consensus report of the World Glaucoma Association. Section V: What Do We Still Need to Know? Kugler Publications: Amsterdam, The Netherlands; 2009:143-153.

73. Plange N, Kaup M, Arend O, et al. Asymmetric visual field loss and retrobulbar haemodynamics in primary open-angle glaucoma. Graefes Arch Clin Exp Ophthalmol. 2006;244;978-983.

74. Zeitz O, Galambos P, Wagenfeld L, et al. Glaucoma progression is associated with decreased blood flow velocities in the short posterior ciliary artery. Br J Ophthalmol. 2006;90;1245-1248.

75. Galassi F, Sodi A, Ucci F, et al. Ocular hemodynamics and glaucoma prognosis: a color Doppler imaging study. Arch Ophthalmol. 2003;121;1711-1715.
76. Martinez A, Sanchez M. Predictive value of colour Doppler imaging in a prospective study of visual field progression in primary open angle glaucoma. Acta Ophthalmol Scand. 2005;83;716-722.

77. Satilmis M, Orgul S, Doubler B, et al. Rate of progression of glaucoma correlates with retrobulbar circulation and intraocular pressure. $\mathrm{Am} \mathrm{J}$ Ophthalmol. 2003;135:664-669.

78. Lam A, Piltz-Seymour J, Dupont J, et al. Laser Doppler flowmetry in asymmetric glaucoma. Curr Eye Res. 2005;30:221-227.

79. Sato EA, Ohtake Y, Shinoda K, et al. Decreased blood flow at neuroretinal rim of optic nerve corresponds with visual field deficit in eyes with normal tension glaucoma. Graefes Arch Clin Exp Ophthalmol. 2006;244:795-801.

80. Sato EA, Shinoda K, Inoue M, et al. Reduced choroidal blood flow can induce visual field defect in open angle glaucoma patients without intraocular pressure elevation following sclera buckling. Retina. 2008;28:493-497.

81. Kozobolis VP, Detorakis ET, Georgiadis GS, et al. Perimetric and retrobulbar blood flow changes following carotid endarterectomy. Graefes Arch Clin Exp Ophthalmol. 2007;245:1639-1645.

82. Martinez A, Sanchez M. Effects of dorzolamide $2 \%$ added to timolol maleate $0.5 \%$ on intraocular pressure, retrobulbar blood flow, and the progression of visual field damage in patients with primary openangle glaucoma: a single-center, 4-year, open-label study. Clin Ther. 2008;30;1120-1134.

83. The European Glaucoma Prevention Study (EGPS) Group. Results of the European Glaucoma Prevention Study. Ophthalmology. 2005;112:366375 .

84. Arend O, Harris A, Wolter P, et al. Evaluation of retinal haemodynamics and retinal function after application of dorzolamide, timolol and latanoprost in newly diagnosed open-angle glaucoma patients. Acta Ophthalmol Scand. 2003;81:47-49.

85. Arend O, Remky A, Cantor LB, et al. Altitudinal visual field asymmetry is coupled with altered retinal circulation in patients with normal pressure glaucoma. Br J Ophthalmol. 2000;84:1008-1012.

86. Martinez A, Sanchez-Salorio. Predictors for visual field progression and effects of treatment with dorzolamide $2 \%$ or brinzolamide $1 \%$ each added to timolol $0.5 \%$ in primary open-angle glaucoma. Acta Ophthalmologica. 2009; DOI:10.111/j/1755-3768.2009.01595.x [Epub ahead of print].

87. Logan JF, Rankin SJ, Jackson AJ, et al. Retinal blood flow measurements and neuroretinal rim damage in glaucoma. Br $J$ Ophthalmol. 2004;88:1049-1054

88. Hafez AS, Bizzarro RL, Lesk MR. Evaluation of optic nerve head and peripapillary retinal blood flow in glaucoma patients, ocular hypertensives, and normal subjects. Am J Ophthalmol. 2003;136:1022-1031.

89. Januleviciene I, Sliesoraityte I, Sieky B, et al. Diagnostic compatibility of structural and hemodynamic parameters in open-angle glaucoma patients. Acta Ophthalmol. 2008;86:552-557.

90. Januleviciene I, Ehrlich R, Siesky B, et al. Visual Funcion, optic nerve structure, and ocular blood flow parameters after 1 year of glaucoma treatment with fixed combinations. Eur J Ophthalmol. 2009;19: $790-797$.
Clinical Ophthalmology

\section{Publish your work in this journal}

Clinical Ophthalmology is an international, peer-reviewed journal covering all subspecialties within ophthalmology. Key topics include: Optometry; Visual science; Pharmacology and drug therapy in eye diseases; Basic Sciences; Primary and Secondary eye care; Patient Safety and Quality of Care Improvements. This journal is indexed on Submit your manuscript here: http://www.dovepress.com/clinical-ophthalmology-journal

\section{Dovepress}

PubMed Central and CAS, and is the official journal of The Society of Clinical Ophthalmology (SCO). The manuscript management system is completely online and includes a very quick and fair peer-review system, which is all easy to use. Visit http://www.dovepress.com/ testimonials.php to read real quotes from published authors. 